\title{
Ontogenic Resistance of Leaves and Fruit, and How Leaf Folding Influences the Distribution of Powdery Mildew on Strawberry Plants Colonized by Podosphaera aphanis
}

\author{
Belachew Asalf, David M. Gadoury, Anne Marte Tronsmo, Robert C. Seem, \\ Andrew Dobson, Natalia A. Peres, and Arne Stensvand
}

First and third authors: Department of Plant and Environmental Sciences, Norwegian University of Life Sciences, 1432 Ås, Norway; first, fifth, and seventh: Norwegian Institute for Agricultural and Environmental Research, Plant Health and Plant Protection Division, 1432 Ås, Norway; second and fourth authors: Department of Plant Pathology and Plant-Microbe Biology, Cornell University, New York State Agricultural Experiment Station, Geneva 14456; and sixth author: Department of Plant Pathology, University of Florida, Gulf Coast Research and Extension Center, Wimauma 33598.

Accepted for publication 20 February 2014.

\begin{abstract}
Asalf, B., Gadoury, D. M., Tronsmo, A. M., Seem, R. C., Dobson, A., Peres, N. A., and Stensvand, A. 2014. Ontogenic resistance of leaves and fruit, and how leaf folding influences the distribution of powdery mildew on strawberry plants colonized by Podosphaera aphanis. Phytopathology 104:954-963.

Ontogenic or age-related resistance has been noted in many pathosystems but is less often quantified or expressed in a manner that allows the concept to be applied in disease management programs. Preliminary studies indicated that leaves and fruit of three strawberry cultivars rapidly acquired ontogenic resistance to the powdery mildew pathogen, Podosphaera aphanis. In the present study, we quantify the development of ontogenic resistance in controlled inoculations of 10 strawberry cultivars using diverse isolates of $P$. aphanis in New York and Florida, USA, and in Norway. We report the differential and organ-specific development of

prior to unfolding of emergent leaves, rather than differential susceptibility of adaxial versus abaxial leaf surfaces, may explain the commonly observed predominance of powdery mildew on the lower leaf surfaces. Susceptibility of leaves and fruit declined exponentially with age. Receptacle tissue of berries inoculated at four phenological stages from bloom to ripe fruit became nearly immune to infection approximately 10 to 15 days after bloom, as fruit transitioned from the early green to the late green or early white stage of berry development, although the achenes remained susceptible for a longer period. Leaves also acquired ontogenic resistance early in their development, and they were highly resistant shortly after unfolding and before the upper surface was fully exposed. No significant difference was found in the susceptibility of the adaxial versus abaxial surfaces. The rapid acquisition of ontogenic resistance by leaves and fruit revealed a narrow window of susceptibility to which management programs might be advantageously adapted.
\end{abstract} ontogenic resistance in the receptacle and externally borne strawberry achenes. We further report that rapid development of ontogenic resistance
Additional keywords: Fragaria $\times$ annanasa, Sphaerotheca macularis.
Powdery mildew of strawberry caused by Podosphaera aphanis (syn. Sphaerotheca macularis) is an important disease of strawberries throughout the range of their cultivation $(21,25)$. The disease has become more problematic in recent years due to widespread resistance to commonly used fungicides $(19,26)$ and a simultaneous trend toward production in high tunnel systems; an environment that generally favors development of powdery mildews $(17,30)$. Strawberry powdery mildew is managed by multiple applications of fungicides (25). Chasmothecia (syn. cleistothecia) have only recently been confirmed as a source of primary inoculum and are capable of releasing ascospores during the earliest stages of plant growth (11). Pathogen populations are heterothallic, and initiation of ascocarps is regulated by temperature (3).

Peries (24) commented upon the greater susceptibility of younger leaves compared with older leaves, but presented no data in support of these observations. Amsalem et al. (1) reported that conidial germination increased from approximately $10 \%$ on leaves borne on younger plants (plants with only three to four leaves) to 24 to $32 \%$ on older plants (plants bearing flowers), but did not distinguish between germination of conidia on emergent,

Corresponding author: B. Asalf; E-mail address: belachew.asalf.tadesse@bioforsk.no

http://dx.doi.org/10.1094/PHYTO-12-13-0345-R

(c) 2014 The American Phytopathological Society expanding or fully expanded leaves. The two to threefold change in the germination rate reported by Amsalem et al. (1) alone could not account for near-absence of infection of mature leaves reported in subsequent studies by Carisse and Bouchard (7). The work by Carisse and Bouchard (7), as well as our preliminary reports $(4,15)$, have quantified the substantial development of ontogenic resistance in strawberry leaves and fruit as these organs age. Widespread application of ontogenic resistance in disease management would be facilitated by demonstrating that the foregoing studies typify disease development on most strawberry cultivars, and to additional isolates of $P$. aphanis. Furthermore, there are unresolved aspects of disease development on strawberry leaves and fruit, particularly as they relate to leaf folding and klendusity, differential susceptibility of the adaxial versus abaxial leaf surfaces, and tissue- and organ-specific development of ontogenic resistance. Strawberry powdery mildew is more commonly found, and disease severity is generally higher on the lower (abaxial) surface of leaves $(21,27)$. Sombardier et al. (27) reported an increase in conidial germination and infection efficiency on the adaxial versus abaxial surfaces of fully expanded strawberry leaves in vitro. The role of differential susceptibility of the abaxial versus adaxial leaf surface in creating such a distribution of infection in vivo and under field conditions remains unclear. Likewise, the susceptibility of the receptacle tissue of fruit compared with the externally situated achenes has not been 
reported. Our hypothesis is that ontogenic resistance and leaf folding together may provide an explanation for an enigmatic distribution of the disease between the adaxial and abaxial leaf surfaces. Cryptic development of powdery mildew on the abaxial leaf surface represents a real risk of underestimating disease, leading to management failures. The objectives of the present studies were (i) to quantify the development of ontogenic resistance in strawberry fruits and leaves of several cultivars of strawberry to $P$. aphanis and (ii) to study the effect of leaf folding on distribution of $P$. aphanis between upper and lower leaf surfaces.

\section{MATERIALS AND METHODS}

Ontogenic resistance on strawberry fruit. Experiments on the development of ontogenic resistance in strawberry fruit were conducted in Norway. Short-day (June-bearing) strawberry cultivars Frida, Inga, and Korona were propagated from runners, and the day-neutral cultivar Elan was grown from seed. Rooted plug plants were planted into individual pots with a commercial soil (P-jord, L.O.G. AS Oslo, Norway) mixed with Perlite (4:1, $\mathrm{vol} / \mathrm{vol}$ ) and were grown in a greenhouse at 18 to $20^{\circ} \mathrm{C}$, with a $16 \mathrm{~h}$ day length. Natural daylight was supplemented (when the level fell below $150 \mathrm{micromole} / \mathrm{m}^{2} / \mathrm{s}$ ) with high-pressure sodium (HPS) lighting delivering $150 \mathrm{micromole} / \mathrm{m}^{2} / \mathrm{s}$ of daylightbalanced illumination. Frida, Inga, and Korona plants were sprayed at planting and Elan plants at emergence of the first true leaf, with penconazole (Topas 100 EC, Syngenta Crop Protection) at $0.25 \mathrm{ml}$ per liter. Plants were thereafter exposed to vaporized sulfur for 3 to $4 \mathrm{~h}$ every evening until flower initiation, whereupon sulfur use was discontinued. The plants were handpollinated with a paintbrush to ensure uniform fertilization and fruit initiation. Approximately 4 weeks elapsed between the penconazole treatment and the earliest inoculations of flowers or fruit, well beyond the time that penconazole would exert a detectable effect on establishment or growth of P. aphanis. Germination and growth of $P$. aphanis conidia was equivalent on treated and untreated plants (D. M. Gadoury, unpublished data). Plants were examined with a $14 \times$ hand lens for signs of $P$. aphanis immediately prior to inoculation to confirm that they appeared to be free of powdery mildew. Thus, the foregoing protocol produced mildew-free and fungicide residue-free plants whereupon the time of inoculation could be established both temporally and phenologically.

Inoculum production was as previously described (4). Briefly, emergent mildew-free Korona leaves were collected and soaked in $0.5 \%$ sodium hypochlorite for $5 \mathrm{~min}$, rinsed three times in distilled water for $2 \mathrm{~min}$, and then air dried for 1 to 2 min under a laminar flow hood. The petioles were removed from leaves, and they were placed within $9 \mathrm{~cm}$ Petri dishes containing $0.5 \%$ water agar amended with $0.03 \%$ benzimidazole (20). The lower surfaces of the leaflets were then inoculated by touching them with a leaf bearing a 5- to 7-day-old sporulating mildew colony and were then incubated in a growth chamber $\left(20^{\circ} \mathrm{C}, 16 \mathrm{~h}\right.$ light: $8 \mathrm{~h}$ dark photoperiod, $80 \%$ relative humidity $[\mathrm{RH}]$ ) for 8 to 10 days until abundant sporulation occurred.
Fruit of all cultivars were inoculated at the following developmental stages: flowering, green fruit, white fruit, and pink fruit (Fig. 1). Flowers were tagged and labeled with the date on which they first opened to allow the age of later-inoculated organs to be expressed both as the above-mentioned developmental stages (Fig. 1) and days after bloom. For each developmental stage to be inoculated (Fig. 1), four plants of each cultivar, each bearing at least five tagged flowers or fruits of a specific developmental stage, were arbitrarily selected. Thus, a replicate consisted of at least five inoculated flowers or fruits of the same age on a single plant of each cultivar. Treatments were replicated four times in a completely randomized design. Flowers and fruit on noninoculated plants served as controls. The entire experiment was conducted twice on each of the four cultivars.

Flowers or fruit that had been previously examined at $14 \times$ to confirm the absence of $P$. aphanis were inoculated by transferring conidia from infected leaflets using a fine artist's paintbrush. Prior evaluation of this method of transfer had indicated that it resulted in approximately the same density of deposition on both leaves and glass slides (D. M. Gadoury, unpublished data). For inoculation of flowers (Fig. 1A), the conidia were applied to the receptacle tissue only, not the corolla. The density of conidia applied to inoculated tissue was estimated by transferring conidia using the same methods to a glass microscope slide. The slide was examined under bright field microscopy, the conidia were counted, and their density per square millimeter was calculated.

Inoculated plants were incubated in a greenhouse at 18 to $20^{\circ} \mathrm{C}$ and $80 \% \mathrm{RH}$, under a $16 \mathrm{~h}$ day with HPS lights to deliver a minimum of $150 \mathrm{micromole} / \mathrm{m}^{2} / \mathrm{s}$ of daylight-balanced illumination. The incidence (percentage of fruits diseased) and severity (percentage of fruit surface colonized by $P$. aphanis) were recorded as each cohort of fruit reached maturity. Severity was assessed with a dissecting microscope. For all four cultivars, disease incidence and severity was assessed on a total of 868 fruits.

Quantification of ontogenic resistance on strawberry leaves, effects of leaf folding, and differential susceptibility of the abaxial and adaxial leaf surfaces. Experiments conducted using the cultivars Earliglow and Elan in New York, USA. Ontogenic resistance was assessed on strawberry leaves of the short-day cultivar Earliglow and the day-neutral F1 hybrid cultivar Elan at New York State Agricultural Experiment Station (NYSAES), Geneva, NY. Earliglow plants were propagated from dormant rooted crowns, whereas Elan plants were raised from seed as previously described. Mildew-free potted plants were inoculated using 7-day-old cultures of $P$. aphanis. Isolates used to propagate inoculum applied to Earliglow or Elan plants were collected from naturally infected field-grown Earliglow or Elan plants, respectively, at NYSAES. Leaves were inoculated at seven developmental stages ranging from the youngest emergent leaf to fully expanded leaves as depicted in Figure 2, and are further described as follows: (i) stage 1, leaves light green, leaflets not separated, leaf lamina highly folded, leaf vertical, blades not reflexed from petiole; (ii) stage 2, leaves light green, leaflets partially separated, lamina unfolded approximately 5 degrees, blades not reflexed


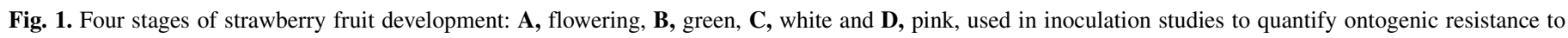
Podosphaera aphanis. 
from petiole; (iii) stage 3, leaves light green, most leaflets separated, lamina unfolded 15 to 30 degrees, blades not reflexed from petiole; (iv) stage 4, leaves light green, leaflets separated, lamina unfolded 30 to 60 degrees, blades slightly reflexed from petiole; (v) stage 5, leaves light green, completely separated, lamina unfolded more than 60 degrees, blades reflexed up to 45 degrees from petiole; (vi) stage 6, similar to stage 5, but leaf blades reflexed 90 degrees from petiole; and (vii) stage 7 , similar to stage 6 but leaves darker green than stage 6 (Fig. 2).

One developmental stage per plant (Fig. 2) was tagged and inoculated within a laminar flow hood. Leaflets were inoculated by transferring chains of conidia from newly sporulating colonies on detached leaves maintained in Petri dishes. The transfer was accomplished with a fine artist's camelhair paintbrush trimmed to retain approximately five hairs. The tip of the brush was lightly touched to the mildew colony and then gently brushed across either the adaxial or abaxial leaflet surface. To access the adaxial surface of the highly folded leaflets in stages 1, 2, and 3 (Fig. 2), the leaflet surfaces were separated using fine-point forceps and the artist's brush was inserted, and lightly touched to the separated surfaces. Three leaflets of four plants were inoculated for each phenological stage (Fig. 2) for each of the two cultivars. The plants were then transferred to growth chambers maintained at $20^{\circ} \mathrm{C}$ and 70 to $80 \% \mathrm{RH}$ for 10 days before they were examined for signs of colonization and sporulation. Sporulation (conidia per square millimeter of colonized tissue) was assessed by pressing a $22 \mathrm{~mm}^{2}$ cover glass to the sporulating surface of the colony, counting the number of conidia in three microscopic fields of the
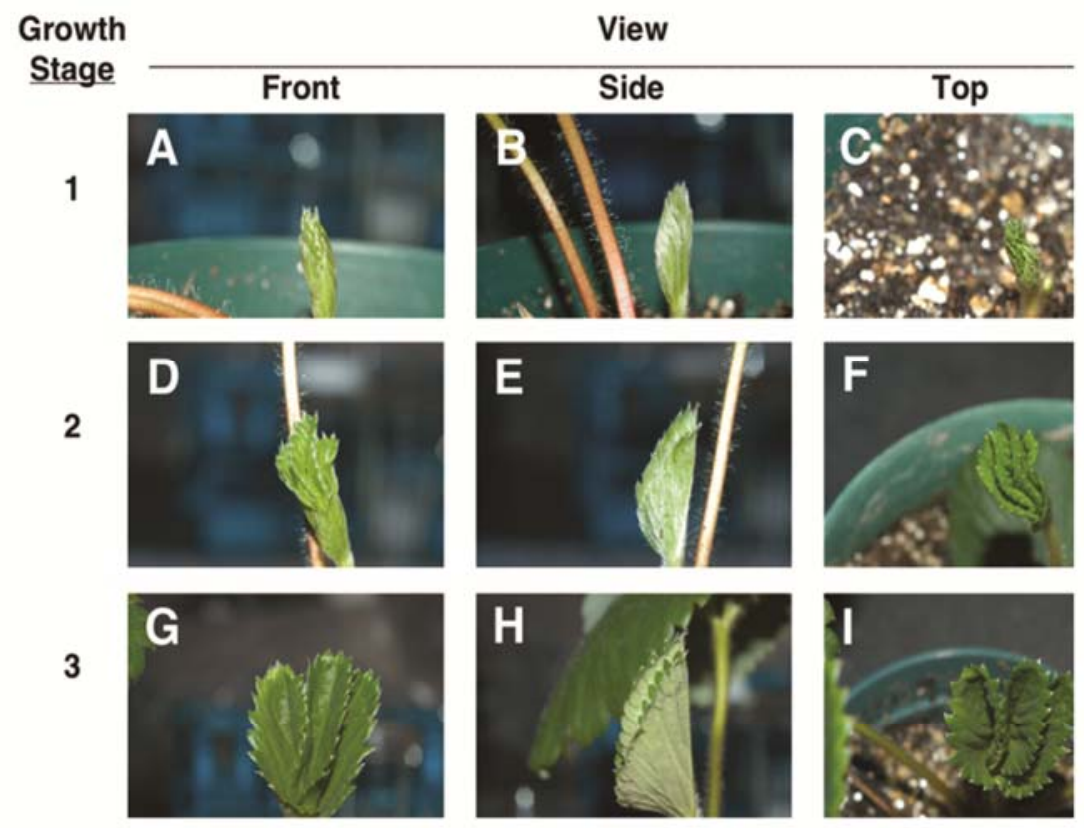

4


Fig. 2. Seven stages of strawberry leaf development used in inoculation studies to quantify ontogenic resistance to Podosphaera aphanis. Leaves of the cultivar Earliglow are shown in front $(\mathbf{A}, \mathbf{D}, \mathbf{G}, \mathbf{J}, \mathbf{M}, \mathbf{P}$, and $\mathbf{S})$, side $(\mathbf{B}, \mathbf{E}, \mathbf{H}, \mathbf{K}, \mathbf{N}, \mathbf{Q}$, and T), and top $(\mathbf{C}, \mathbf{F}, \mathbf{I}, \mathbf{L}, \mathbf{O}, \mathbf{R}$, and $\mathbf{U})$ view. 
cover glass at 100 to $800 \times$ using bright field microscopy, and correcting for the area examined. Noninoculated plants served as experimental controls. The experiment was conducted three times on Earliglow and three times on Elan.

To assess the combined effect of ontogenic resistance and leaf folding upon the distribution of symptoms of plants exposed to airborne inoculum, seven potted Earliglow plants, each bearing two previously tagged trifoliate leaves in one of the above stages of development (Fig. 2) were placed in a wind tunnel approximately $3 \mathrm{~m}$ downwind of a fan generating a wind speed within the tunnel of approximately $8 \mathrm{~km} / \mathrm{h}$. Three heavily mildewed Earliglow plants were placed immediately in front of the fan for $5 \mathrm{~min}$ as a source of airborne inoculum for the downwind plants. Three microscope cover glasses $(24 \times 50 \mathrm{~mm})$ were placed next to each set of downwind plants to determine the density of spore deposition to which leaves were exposed. These cover glasses were placed in Petri dishes containing moist filter paper and were incubated at $22^{\circ} \mathrm{C}$ for $24 \mathrm{~h}$ before they were examined under bright field microscopy at $100 \times$, and the number of germinated and nongerminated conidia per cover glass was recorded. The first downwind set of plants was then removed and replaced by a second set, likewise exposed for $5 \mathrm{~min}$ and removed, and then a third set of plants was placed in the tunnel for $5 \mathrm{~min}$ and were then removed. Thus, treatments (leaf developmental stages) were replicated on three plants, each bearing two trifoliate leaves at one of the developmental stages shown in Figure 2. Inoculated plants were placed in a plant growth chamber at $20^{\circ} \mathrm{C}$ for 7 days with a $16 \mathrm{~h}$ day length. Seven days after inoculation, the severity of powdery mildew was recorded on the abaxial and adaxial surface of five trifoliate leaves of each developmental stage. The experiment was conducted twice, and then repeated twice more with the following modifications: (i) inoculated plants were of the cultivar Elan, and (ii) inoculated plants were incubated for 10 days before severity of infection was assessed.

Experiments conducted using the cultivars Frida, Inga, Korona, and Senga Sengana in Norway. Development of ontogenic resistance was assessed at the Norwegian University of Life Sciences (UMB) in Ås, Norway on cultivars Frida, Inga, Korona, and Senga Sengana using methods similar to those employed at NYSAES with the following modifications. (i) All old leaves were trimmed and the plants were kept in a clean room until they had five or more leaves. Five leaf stages were tagged on the same plant corresponding to stages 2, 3, 5, 6, and 7 (Fig. 2), and whenever a plant did not contain all five stages, the required leaf stages were tagged on other plants. (ii) There were four replicates, and a replicate contained five plants (15 leaflets of each phenological stage) for all cultivars with the exception of cultivar Inga in experiment 2 where four plants (12 leaflets of each phenological stage) were used per replication. (iii) Only the abaxial surfaces of the leaflets were inoculated. (iv) For all four cultivars, disease incidence and severity was assessed on 2,340 leaflets (experiments 1 and 2 combined), 21 days after inoculation under a dissecting microscope. (v) Sporulation was assessed as the percentage of the colonized area bearing conidiophores. (vi) The experiment was conducted in a greenhouse maintained at 18 to $20^{\circ} \mathrm{C}, 80 \% \mathrm{RH}$, and $16 \mathrm{~h}$ daylight period with a minimum of 150 micromole $/ \mathrm{m}^{2} / \mathrm{s}$ of daylight-balanced illumination supplied by HPS lamps if necessary. (vii) Isolates used to propagate inoculum applied to Frida, Inga, Korona, or Senga Sengana was collected, respectively, from naturally infected plants of the same cultivar. (viii) The experiment was conducted twice on each of the four cultivars.

Experiments conducted using the cultivars Strawberry Festival, San Andreas, Treasure, and Albion in Florida, USA. Development of ontogenic resistance was similarly assessed at the University of Florida Gulf Coast Research and Extension Center (GCREC) in Wimauma, Florida, on cultivars Festival, San Andreas, Treasure, and Albion, using methods similar to those employed at NYSAES with the following modifications: (i) on four separate plants, leaf stages 2, 3, 4, 5, 6, and 7 (Fig. 2) were tagged and the adaxial surface of tagged leaflets were inoculated as above; (ii) isolates used to propagate inoculum applied to Festival, San Andreas, Treasure, and Albion were collected, respectively, from naturally infected plants of the same cultivar; (iii) For all four cultivars, the plants were incubated in a growth chamber at $18^{\circ} \mathrm{C}, 70 \% \mathrm{RH}$ and sporulation was assessed 7 days after inoculation by detaching an inoculated leaf, placing the leaf in a centrifuge tube with $5 \mathrm{ml}$ of water with agitation, after which a 5 - $\mu$ l sample of the resultant suspension was examined microscopically at $400 \times$, and the conidia were enumerated. Tween $20(0.05 \%)$ was used as wetting agent. Fresh weight of each leaf at the time that sporulation was assessed was also recorded. The experiment was conducted twice.

Data analysis. Both severity and incidence data were transformed using $\log (x+1)$ when there was a deviation from the assumption of normal distribution of variances. The interaction of cultivar by fruit age was analyzed using the generalized linear model (GLM) option of Minitab version 16 (23). Significant differences among cultivars at bloom or green fruit growth stage inoculation were determined using analysis of variance. Following one-way analysis of variance procedure, means were compared using Tukey's test with $P=0.05$ (23).

In the regression analysis, when the residual plot revealed nonrandom pattern of data distribution, the data were transformed by nonlinear transformations to achieve linearity. The transformation that gave the highest coefficient of determination $\left(R^{2}\right)$ value was selected. The degree days required to reach each fruit developmental stage were determined and used in the regression of degree days against disease incidence or disease severity. Disease severity and incidence of each cultivar from the two experiments were pooled. After pooling the data, the severity and incidence at the bloom stage inoculation were scaled to $100 \%$ and the value for other fruit growth stages were scaled proportionally. After pooling and scaling the data were square root transformed and regressed against the degree-day data.

For the leaf ontogenic resistance, the number of days required to advance through the leaf developmental stages (Fig. 2) for each cultivar was recorded for leaves tagged on 10 plants in New York and Norway. Similar to the fruit data, disease severity and incidence data of leaves from the two experiments were pooled and the maximum severity and incidence value set to $100 \%$ and other values scaled proportionally. The data were regressed against the degree-day data and fitted with nonlinear regression. Similarly, after confirming homogeneity of variance, the sporulation data from both cultivars in New York were pooled, sporulation at stage 1 was set equal to $100 \%$, and sporulation at later leaf stages was scaled to this value. Sporulation was regressed against degree day accumulations (base $=5^{\circ} \mathrm{C}$ ) from leaf stage 1 for leaves at all subsequent stages of development.

\section{RESULTS}

Ontogenic resistance of strawberry fruits. Inspection of plants at $14 \times$ magnification prior to inoculation confirmed that they were free of visible signs of powdery mildew. The density of inoculation on the leaf or fruit, estimated from deposition of conidia on glass slides and leaf surfaces employed in the experiment, ranged within $\pm 50 \%$ of $4.6 \times 10^{4}$ conidia $/ \mathrm{cm}^{2}$. Incidence and severity of infection was highest on plants that were inoculated at bloom (Fig. 3), but both declined similarly and rapidly through the green fruit stage (Fig. 3). Only fruit of the cultivars Inga and Frida supported detectable levels of powdery mildew when inoculated at the white berry stage (Fig. 3), and none of the cultivars became infected when fruit were inoculated at the pink berry stage (Fig. 3). There was a significant cultivar by fruit age interaction $(P=0.001)$ on disease severity and incidence. When comparing cultivars at the bloom stage inoculation, both 
incidence and severity were significantly $(P=0.05)$ lower on the cultivar Elan than on Inga, Frida, or Korona (Fig. 3). There was a significant $(P=0.001)$ difference in disease severity between the bloom and green stage inoculation for all cultivars (Fig. 3) and also between the green and white stage inoculations except for Inga (Fig. 3). There was no difference between white and pink stage inoculations $(P=0.05)$ for any cultivar.

When resistance was expressed as a proportion of the level of infection at the most susceptible stage of berry development (bloom) and results from the four cultivars were pooled and analyzed by regression, the following models were generated: $Y=$ $10.27-0.026 X$, where $Y$ is the square root of the incidence of infection (percentage of fruit infected), and $X$ equals degree days (base $=5^{\circ} \mathrm{C}$ ) accumulated since bloom, $R^{2}=0.915$ (Fig. 4A); and $Y=9.44-0.025 X$, where $Y$ is the square root of the severity of infection (percentage of berry surface area supporting sporulating colonies) and $X$ equals degree days (base $=5^{\circ} \mathrm{C}$ ) accumulated since bloom, $R^{2}=0.90$ (Fig. $4 \mathrm{~B}$ ).

Inoculation of blossoms on Frida resulted in aborted fertilization of flowers, and the fruit failed to develop further, whereas berries of the cultivar Inga inoculated at the same stage supported profuse sporulation, and berries continued to develop (Fig. 5C). Inoculation of fruit at the green stage resulted in reduced colony expansion and restriction of the colony to the tissue immediately adjacent to the site of inoculation (Fig. 5D), wherein the receptacle tissue prematurely turned pink at the site of infection (Fig.
$5 \mathrm{~B}$ and D). Achenes remained susceptible longer than the receptacles. Severely infected berries developed cracks on fruit surfaces (Fig. 5F). Inoculation of Korona and Elan at the green stage and inoculation of Frida and Inga at the white stage resulted in infection of achenes but not the receptacle.

Ontogenic resistance on strawberry leaves, effects of leaf folding, and differential susceptibility of the abaxial and adaxial leaf surfaces. Experiments conducted using the cultivars Earliglow and Elan in New York. Irrespective of the stage of development at the time of inoculation the susceptibility of the adaxial and abaxial surfaces of Earliglow and Elan leaves did not differ significantly $(P=0.05)$. The number of conidia produced per square millimeter of colonized tissue declined rapidly as leaves were inoculated at sequentially later stages in their development (Fig. 6), but at no stage of development was there significantly greater sporulation per unit of leaf area on the lower (abaxial) compared with the upper (adaxial) leaf surface of Earliglow (Fig. 6A) or Elan (Fig. 6B). Regression of relative sporulation against degree days accumulated between leaf stages 1 through 5 yielded the following model: $Y=101.8-0.682 X$, where $Y$ is the relative sporulation of Eariglow or Elan and $X$ is degree days (base $=5^{\circ} \mathrm{C}$ ) accumulated since leaf developmental stage $1, R^{2}=0.964$ (Fig. 7).

The density of conidia deposited on glass microscope slides exposed to airborne inoculum in the wind tunnel experiments ranged from approximately 51 to $186 \mathrm{conidia} / \mathrm{cm}^{2}$, and the rate of
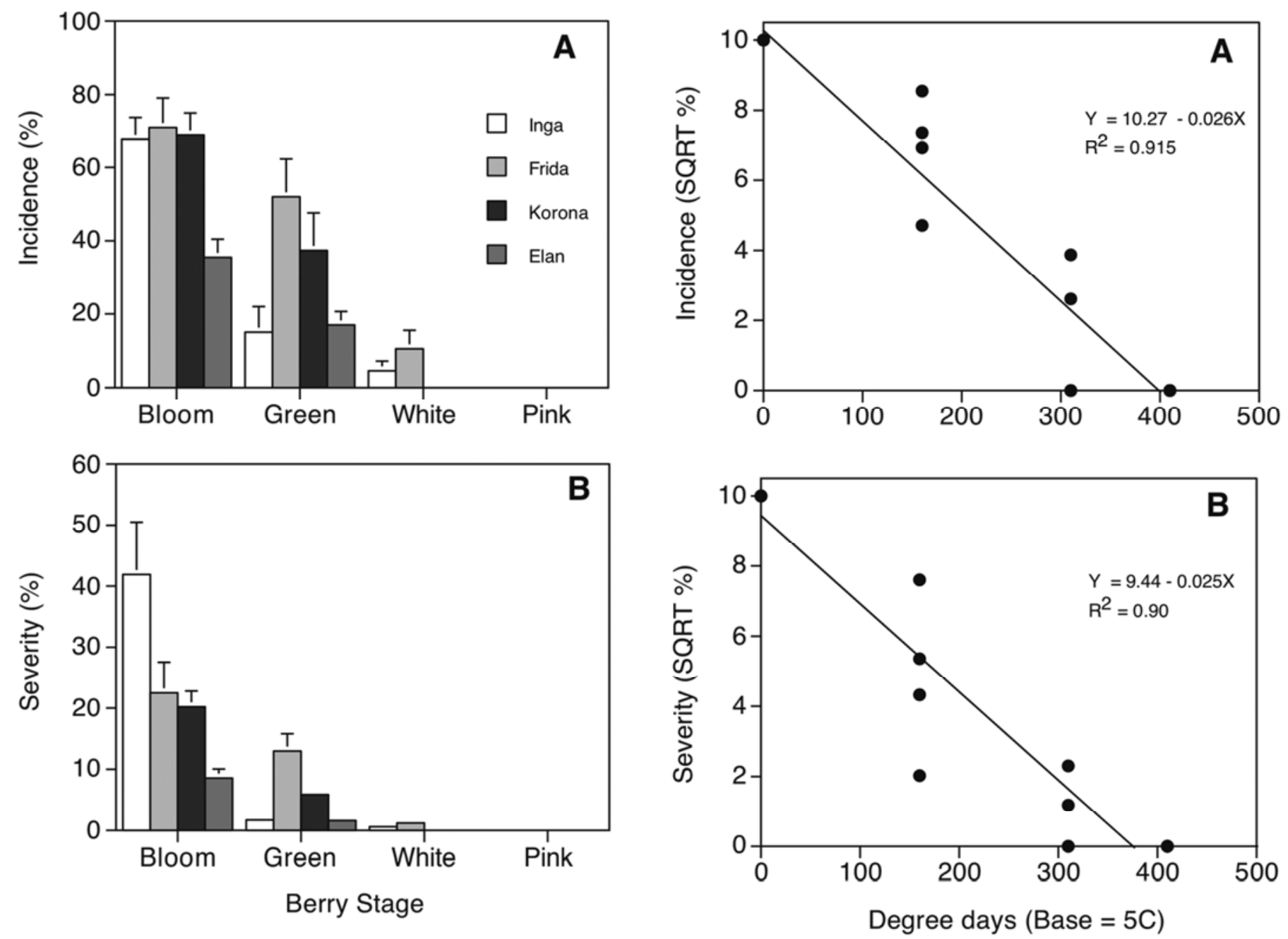

Fig. 3. A, Effect of ontogenic resistance on incidence and $\mathbf{B}$, severity of powdery mildew (Podosphaera aphanis) that developed on fruits of four strawberry cultivars inoculated at different stages of growth. Bars indicate one standard error of the mean.

Fig. 4. Relationship between A, berry age (degree days after flowering) and incidence and $\mathbf{B}$, berry age and severity of strawberry powdery mildew (Podosphaera aphanis). 
germination for conidia collected on these slides ranged from approximately 56 to $83 \%$ after incubation at $22^{\circ} \mathrm{C}$ for $24 \mathrm{~h}$. When potted plants of the cultivars Earliglow and Elan were exposed to airborne conidia in a wind tunnel, infection of stage 1 and stage 2 leaves, which were highly folded at the time of exposure (Fig. 2), was confined primarily to the abaxial (lower) leaf surface (Fig. 8). However, stage 4 leaves, which were unfurled at the time of exposure (Fig. 2), were equally diseased on both the adaxial and abaxial leaf surfaces. On both Earliglow and Elan leaves at stage 3 , a transitional stage that was partially unfurled, the incidence of infection on the abaxial surface was approximately twice that observed on the adaxial surface (Fig. 8).

Experiments conducted using the cultivars Frida, Inga, Korona, and Senga Sengana in Norway. Whether disease was expressed as
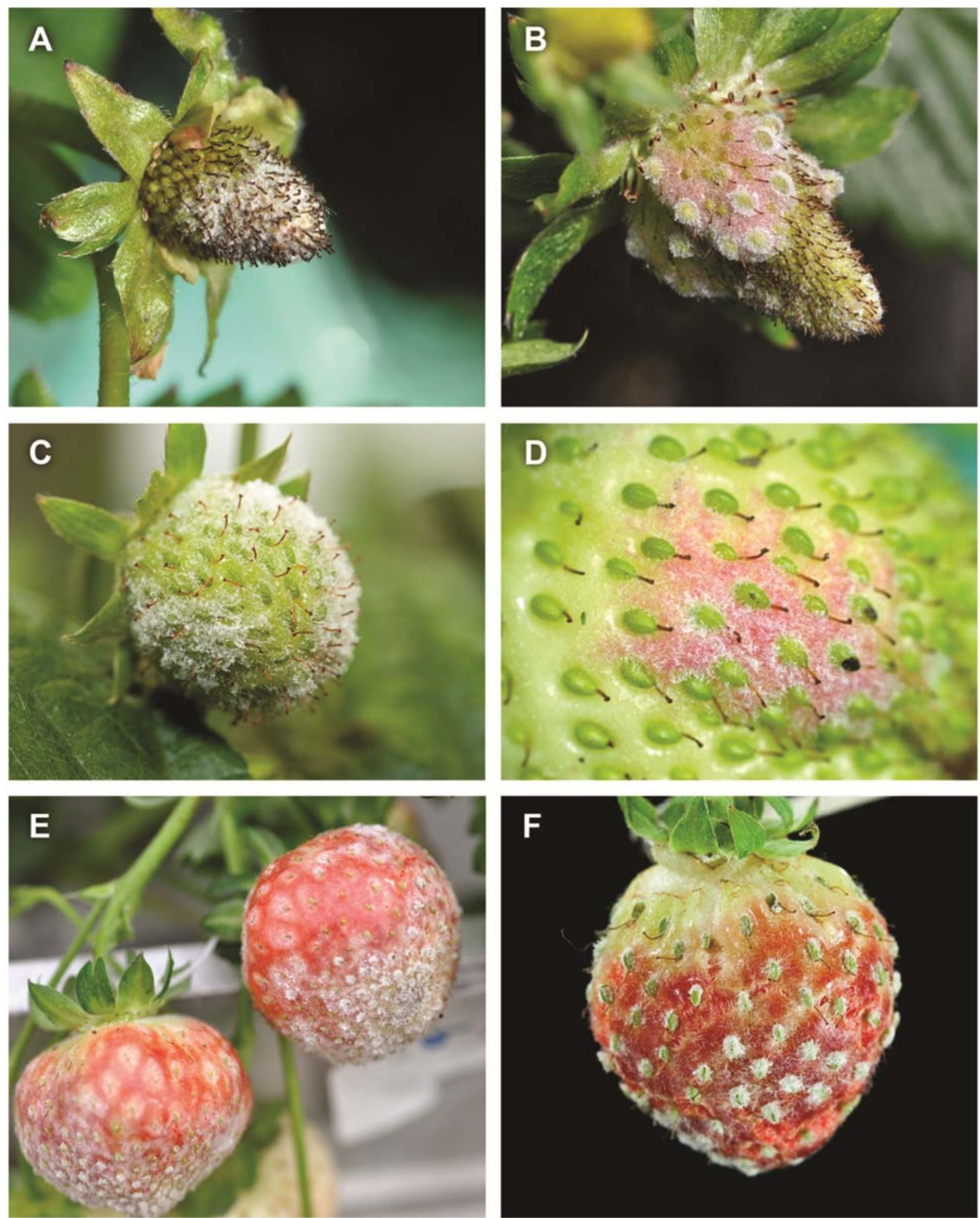

Fig. 5. Infection on fruits inoculated at the bloom and green fruit stages. A to C, Effect of flowering inoculation early in fruit development. D, Green stage inoculation infection was restricted to the area of inoculation, and receptacle tissue turned pink prematurely. $\mathbf{E}$ and $\mathbf{F}$, Mildew on ripe fruit at harvest inoculated at flowering. F, Fruit cracked and looked seedy. 
incidence or severity, susceptibility of strawberry leaves of Inga, Frida, Korona, and Senga Sengana decreased rapidly as leaves aged (Fig. 9). There was a significant interaction between cultivar and leaf developmental stage upon disease severity and incidence $(P=0.01)$. Both disease incidence and severity of stage 2 leaves was significantly $(P=0.001)$ higher than the other leaf growth stages (Fig. 9). On stage 2 leaves (Fig. 2), incidence of powdery

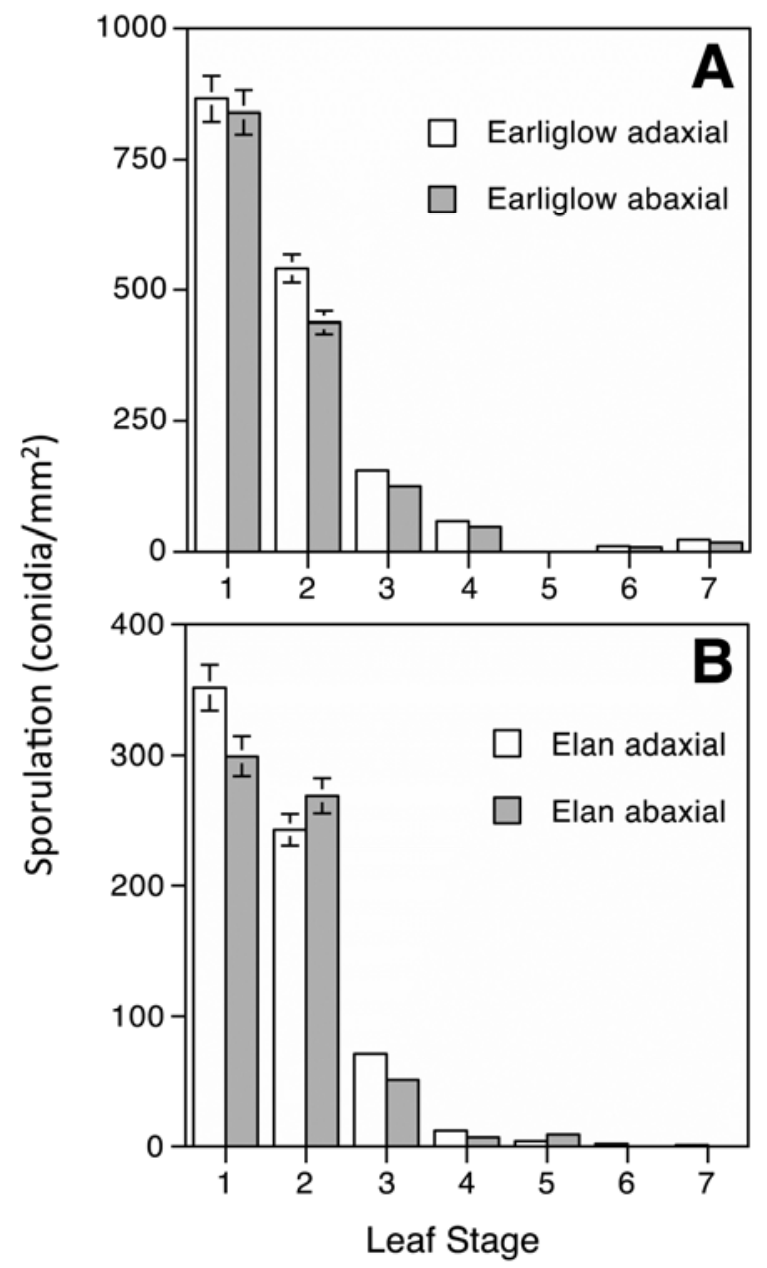

Fig. 6. Effect of leaf age on sporulation of Podosphaera aphanis. Leaves of the cultivars A, Earliglow and B, Elan were inoculated at the indicated stages and incubated for 10 days at $20^{\circ} \mathrm{C}$ and 70 to $80 \%$ relative humidity. Leaf growth stages are presented in Figure 2.

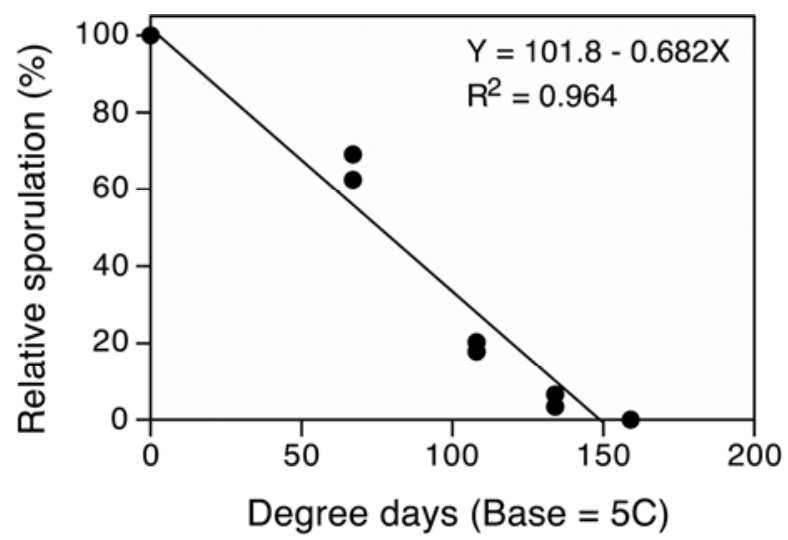

Fig. 7. Decline in susceptibility of foliage of the cultivars Earliglow and Elan inoculated at varying times after emergence expressed as relative sporulation of Podosphaera aphanis. mildew among cultivars ranged between 79 and 93\% (Fig. 9A), and severity ranged from 16 to $27 \%$ (Fig. 9B). Leaves became highly resistant to infection between leaf stages 3 and 5 (Figs. 2 and 9), approximately between 7 to 10 days after emergence at an incubation temperature of $18^{\circ} \mathrm{C}$.

When resistance was expressed as a proportion of the level of infection at the most susceptible stage of leaf development (stage 2) and results from the four cultivars were pooled and analyzed by nonlinear regression, the following models were generated: $Y=2,662 \times 10^{-0.020 X}$, where $Y$ is the incidence of infection (percentage of leaflets infected), and $X$ equals degree-days (base $=$ $5^{\circ} \mathrm{C}$ ) accumulated since leaf emergence, $R^{2}=0.95$ (Fig. 10A); and $Y=3,159 \times 10^{-0.024 X}$, where $Y$ is the severity (percentage of leaflet area supporting sporulating colonies) and $X$ equals degree days (base $=5^{\circ} \mathrm{C}$ ) accumulated since leaf emergence, $R^{2}=0.86$ (Fig. 10B).

Experiments conducted using the cultivars Festival, San Andreas, Treasure, and Albion in Florida. A decline in susceptibility of leaves, expressed as sporulation 7 days after inoculation, was observed in the cultivars Festival, San Andreas, Treasure, and Albion (Fig. 11). The decline in leaf susceptibility, expressed as sporulation, was less rapid between stages 2 and 3 than was observed in the New York and Norway experiments, although relative sporulation declined by over $50 \%$ between stages 2 and 4 on all four cultivars (Fig. 11), and sporulation on the stage 7 leaves (Fig. 2) was less than $10 \%$ of that recorded on

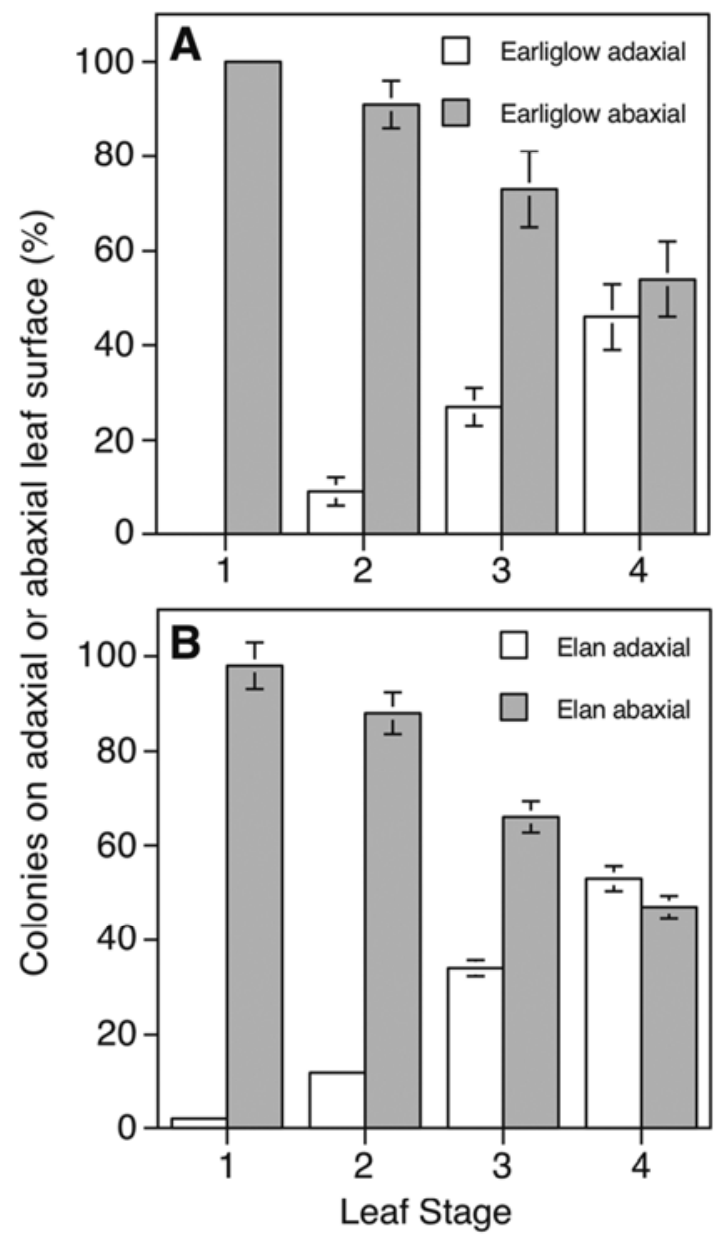

Fig. 8. Effect of leaf folding and leaf age on relative incidence of infection of $\mathbf{A}$, Earliglow and B, Elan strawberry plants exposed to airborne conidia in a wind tunnel. The highly folded leaf stages 1 and 2 were primarily infected on the abaxial (lower, exposed) surface, but once unfolding was complete at stage 4 , there was no significant difference in the incidence of infection between the adaxial and abaxial leaf surfaces. Error bars indicate one standard error of the mean. Leaf growth stages are presented in Figure 2. 
stage 2 leaves (Fig. 11). Mean sporulation on the most susceptible (stage 2) leaf differed substantially among the four cultivars: 71.5, 2,514, 319, and 584 conidia/mg of leaf for Festival, San Andreas, Treasure, and Albion, respectively.

\section{DISCUSSION}

Across a broad range of response variables, including disease incidence, disease severity sporulation per unit of leaf area, sporulation per unit of leaf weight, and development on the abaxial versus adaxial leaf surface, both leaves and fruit of strawberry strongly expressed ontogenic resistance relatively early in their development. The noted responses were also consistent across cultivars, across the isolates employed, and between the various research sites. Thus, development of ontogenic resistance would appear to be both a robust and biologically consistent process within cultivated strawberry. Several previous reports indicated that susceptibility of strawberry fruit to powdery mildew extended to later and in some cases all stages of development $(1,6,16,21)$. In our study, strawberry fruit in the cultivars Inga, Frida, Korona, and Senga Sengana developed ontogenic resistance against P. aphanis approximately 10 to 15 days after bloom. Development of ontogenic resistance of strawberry fruit in the cultivars Jewel and Seascape reported by Carisse and Bouchard (7) followed a similar trend, but with the highest level of resistance expressed at the early pink stage of fruit development in their study (7), compared with the late green to early white stage of fruit development
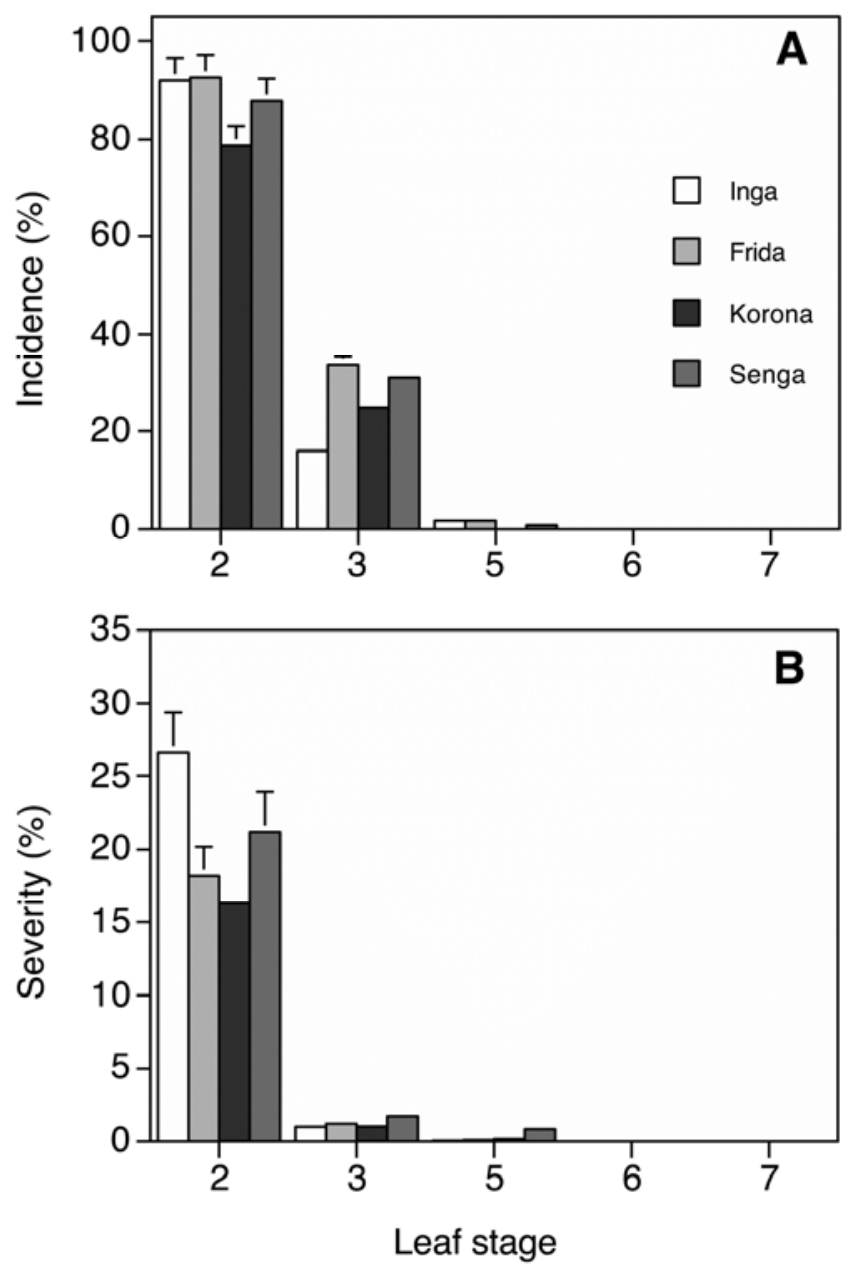

Fig. 9. Effect of ontogenic resistance on $\mathbf{A}$, incidence and $\mathbf{B}$, severity of powdery mildew (Podosphaera aphanis) that developed on leaves of four strawberry cultivars inoculated at different stages of growth. Leaf growth stages are presented in Figure 2. Bars indicate one standard error of the mean. in our study (Fig. 3). At a practical level, given the slope of the exponential decline in fruit susceptibility in both studies, the temporal differences in the time of onset are probably no more than 2 to 3 days. Carisse and Bouchard (7) relied upon both artificial and naturally dispersed inoculum in field plantings in their experiments, while we employed artificial inoculations of plants maintained in a controlled environment. Thus, the relatively small temporal differences noted could easily be attributed to differences between the design and conduct of the respective studies, rather than differences in the pattern of development of ontogenic resistance. Overall, the temporal consistency in development of ontogenic resistance in strawberry fruit should facilitate the broad application of the quantification of ontogenic resistance in disease management programs.

The receptacle tissue of all cultivars became highly resistant to infection at the white fruit stage, but the achenes of some cultivars remained susceptible at later stages. Notably, this protracted susceptibility of the achenes was observed on the cultivars Inga and Frida, but to a lesser degree on Korona and Elan. Such organspecific and temporally diverse development of ontogenic resistance within complex fruit structures has been previously observed in the differential development of ontogenic resistance of grapevine berries and rachis tissue, wherein the rachis of Vitis labrusca cultivars remains susceptible to Erysiphe necator long after the berry epidermis becomes functionally immune (12). The rapid expression of ontogenic resistance in strawberry fruit is similar to that seen in grape berries to E. necator $(10,13)$ and in
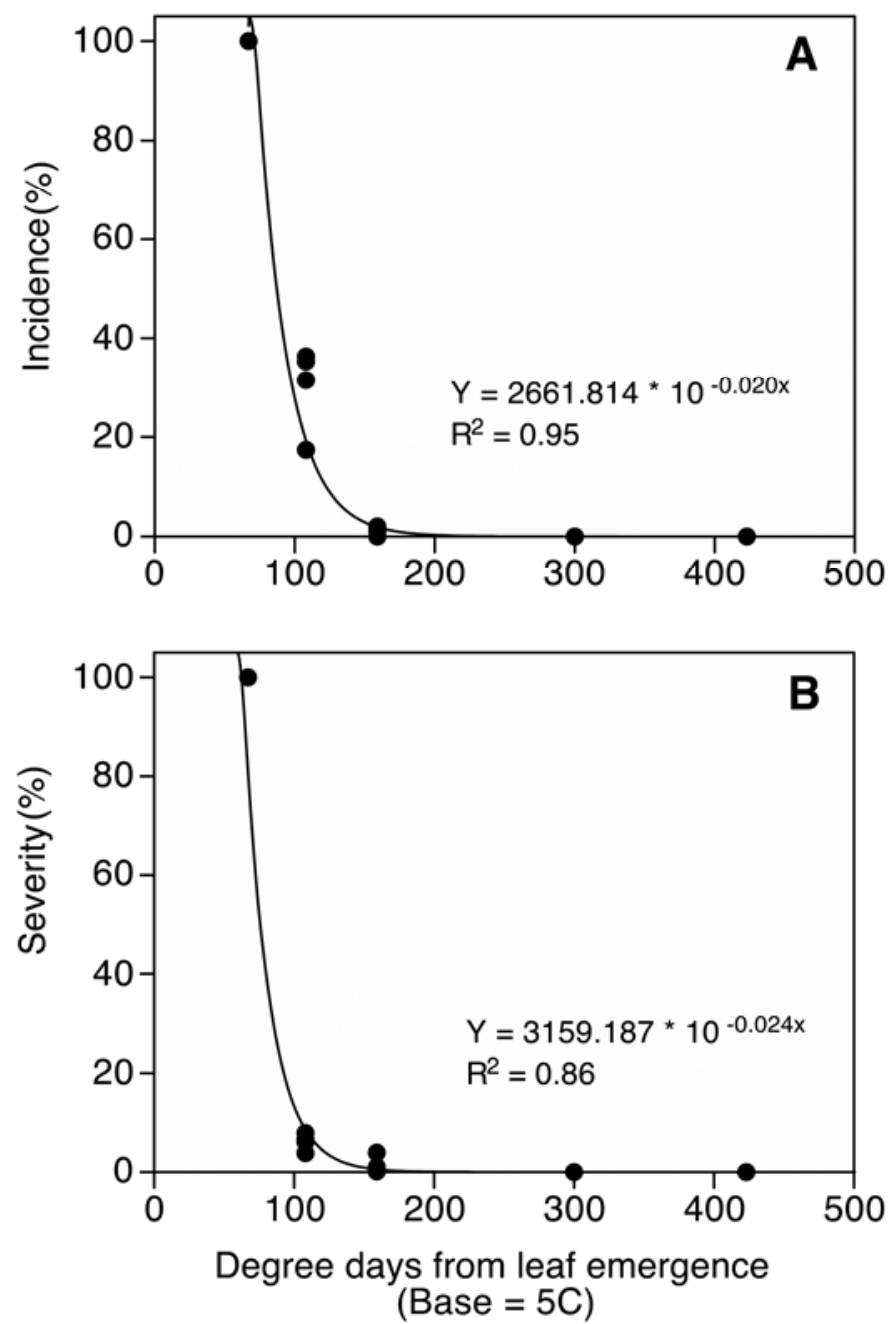

Fig. 10. Relationship between A, leaf age (degree days after leaf emergence) and incidence and $\mathbf{B}$, leaf age and severity of strawberry powdery mildew. 
cucumber fruits to Phytophthora capsici (2). The protracted susceptibility of the achenes could have several deleterious consequences: (i) the infected achene could serve as a base from which the pathogen could grow onto the otherwise resistant receptacle tissue; (ii) tissue of the damaged achene could be colonized by necrotrophic microorganisms, as has been reported for trace levels of E. necator on grape berries (14); and (iii) visible infection of the achenes could affect market value of the harvested crop.

As was the case in development of ontogenic resistance in strawberry fruit, the temporal distribution of ontogenic resistance observed by us across a diverse range of 10 cultivars was consistent with trends reported by Carisse and Bouchard (7) for cultivars Jewel and Seascape. Slight differences in methodology and the means by which data were expressed in the two studies

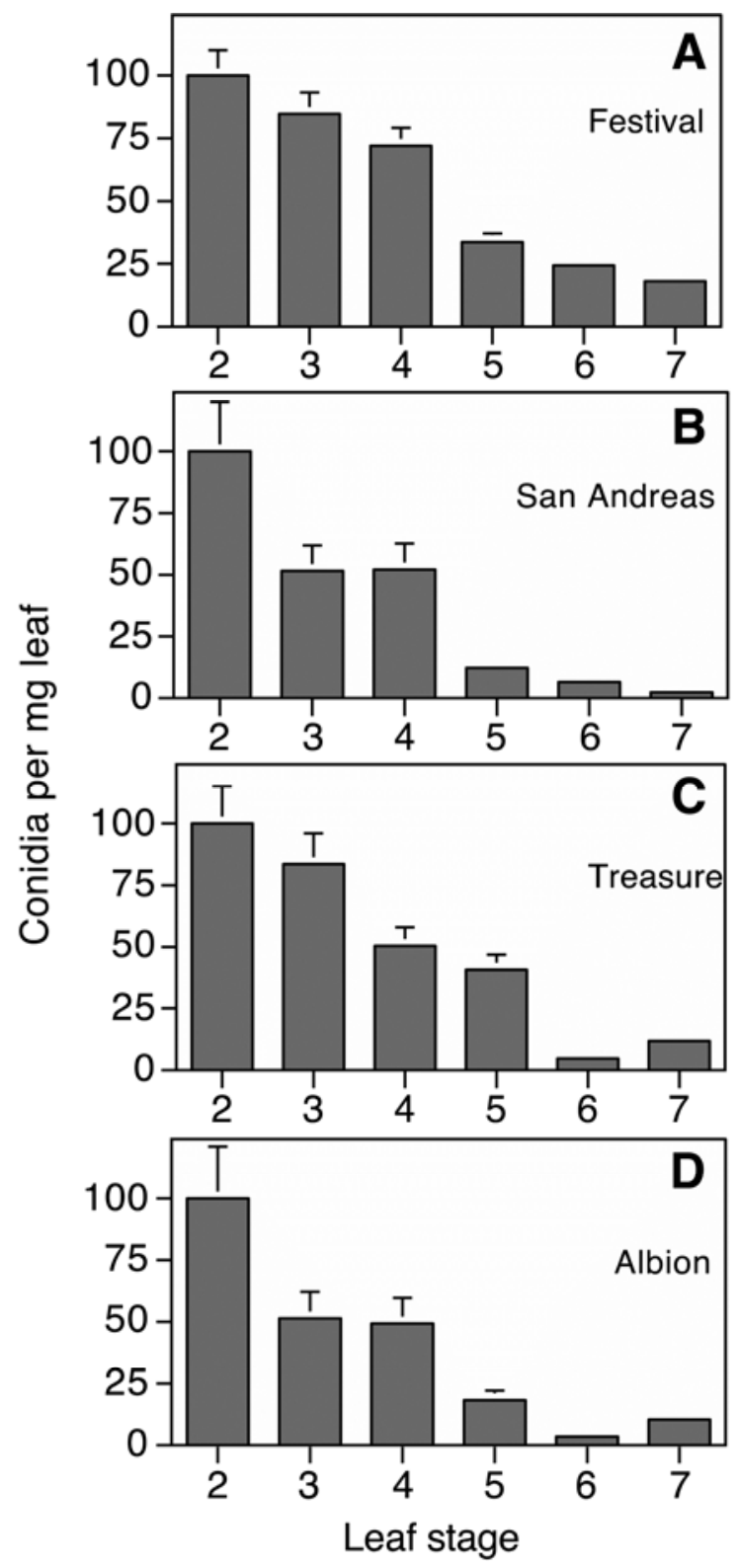

Fig. 11. Effect of leaf age at the time of inoculation on sporulation of Podosphaera aphanis expressed as conidia produced per milligram of leaf fresh weight. The adaxial surface of leaflets of strawberry cultivars A, Strawberry Festival, B, San Andreas, C, Treasure, and D, Albion were inoculated, incubated at $18^{\circ} \mathrm{C}$ and $70 \%$ relative humidity for 7 days, and then sporulation was assessed. Sporulation is expressed as a percentage of the quantity observed on the most susceptible (stage 2) leaflet. Bars indicate one standard error (SE) of the mean, where the magnitude of SE was sufficient to display graphically. Leaf growth stages are presented in Figure 2. may have enhanced or diminished the magnitude of the effects of ontogenic resistance reported. For example, the more gradual acquisition of ontogenic resistance in four cultivars in our Florida experiments may reflect two relevant factors: first, the relative sporulation is based upon comparisons to leaf stage 2 rather than leaf stage 1 (Fig. 11). Second, the data are expressed as sporulation per milligram of leaf fresh weight at 7 days after inoculation. Thus, most susceptible leaflets not fully expanded at the time of inoculation, would continue to grow and expand, and thereby reduce the relative response when compared with leaves that were fully expanded at the time of inoculation. In a similar manner, the youngest leaf stage selected for inoculation in our study (Fig. 2) appeared to be slightly younger and more highly folded than that reported by Carisse and Bouchard (7). Using a younger and therefore more susceptible leaf stage (e.g., our stage 1 versus stage 2 shown in Figure 2) as the basis for scaling of a response in all subsequent leaf stages could slightly decrease the apparent rate of decline in susceptibility with increasing leaf age. For example, we reported relative levels of sporulation on leaf stage on cultivar Treasure (Fig. 11C) of 100, 83, 50, 37, and 6\% on leaf stages 2 to 6 , respectively. At the equivalent stages of leaf development for their study, Carisse and Bouchard (7) reported, in their Table 2, predicted declines in relative disease severity of $100,65,34,18$, and $7 \%$, respectively, for cultivar Jewel. As above in the case of strawberry fruit, such consistency of response in the acquisition of foliar ontogenic resistance across a broad range of cultivars exposed to diverse isolates and experimental conditions should facilitate the confident inclusion of ontogenic resistance as a component of management of strawberry powdery mildew.

Previous reports have indicated that older leaves of strawberry are more resistant than younger leaves $(1,7,24)$, and that the lower leaf surface may be more susceptible to infection than the upper leaf surface. The present study has revealed a mechanism by which the differential severity of disease on upper and lower leaf surfaces can be explained based upon ontogenic resistance, leaf folding, and escape from infections. Our results indicate that the high degree of leaf folding in the earliest developmental stages, which is a universal character of cultivated strawberries, is directly responsible for the absence of disease on the upper leaf surfaces when leaves are exposed to airborne conidia. Essentially, the upper leaf surface is inaccessible to the inoculum while folded, and is ontogenically resistant to infection by the time the leaf is unfolded. Under field conditions, there may be additional factors that contribute to reduction of infection on the upper leaf surface, such as exposure to UV radiation $(18,28,29)$. Leaf folding and the resultant cryptic development of powdery mildew beneath an otherwise healthy appearing canopy has an important implication for management of the disease, as the pathogen's presence is not only obscured, but it also presents a more challenging target for fungicide applications to control powdery mildew. Earlier reports of 10 to $20 \%$ increases in the germination rate of conidia on the adaxial versus abaxial surfaces of fully expanded leaves in vitro (27), or increased infection efficiency on the adaxial surfaces of fully expanded leaves (27) seem unlikely to primarily account for the magnitude of the increased severity of powdery mildew on the lower leaf surfaces in our study (Fig. 8), as the former effect is disproportionately small compared with the increase in severity, and the latter effect is not relevant to the critically susceptible stage wherein the infection court is inaccessible due to leaf folding.

We have reported a preliminary and general degree-day model for development of ontogenic resistance on fruits and leaves. In our experiment the fruits became ontogenically resistant when the berry turned to the white stage, which is approximately 300 degree days with a base temperature of $5^{\circ} \mathrm{C}$. Development of ontogenic resistance has been described in many host pathosystems and is an important component of management programs $(8-10,13,14)$. On all but the most disease-resistant strawberry 
cultivars, $P$. aphanis is presently suppressed by multiple applications of fungicides timed to protect the strawberry plant, including fruit, throughout the flowering and fruiting period $(7,22,25)$.

Growth of both short-day and day-neutral strawberry cultivars is typified by production of successive, overlapping cohorts of leaves and fruits (21). Rates at which new leaves and fruit are produced are predictable within certain groups of cultivars (day neutral versus short day) within a given production system (e.g., annual production on raised plastic-covered beds), but are not linear throughout a growing season (21). Our results indicate that each leaf or fruit has a relatively narrow temporal window of susceptibility to powdery mildew. Ultimately, models of ontogenic resistance in the strawberry powdery mildew pathosystem will require integration with plant growth as a requisite for application in disease management, particularly with respect to fungicide applications to suppress infection at critical stages of an epidemic.

\section{ACKNOWLEDGMENTS}

This work was supported by the Research Council of Norway, the Norwegian University of Life Sciences, and Bioforsk. Additional support for the work was provided through the United States Department of Agriculture Crops at Risk competitive grants program, and the competitive grants program of the North American Strawberry Growers Association. We thank M. C. Heidenreich, G. Lynch, L. Buerman, and T. Seijo for excellent technical assistance.

\section{LITERATURE CITED}

1. Amsalem, L., Freeman, S., Rav-David, D., Nitzani, Y., Sztejnberg, A., Pertot, I., and Elad, Y. 2006. Effect of climatic factors on powdery mildew caused by Sphaerotheca macularis f. sp. fragariae on strawberry. Eur. J. Plant Pathol. 114:283-292.

2. Ando, K., Hammar, S., and Grumet, R. 2009. Age-related resistance of diverse cucurbit fruit to infection by Phytophthora capsici. J. Am. Soc. Hort. Sci. 134:176-182.

3. Asalf, B., Gadoury, D. M., Tronsmo, A.-M., Seem, R. C., CadleDavidson, L., Brewer, M. T., and Stensvand, A. 2013. Temperature regulates the initiation of chasmothecia in powdery mildew of strawberry. Phytopathology 103:717-724.

4. Asalf, B., Stensvand, A., Gadoury, D. M., Seem, R. C., Dobson, A., and Tronsmo, A. M. 2009. Ontogenic resistance to powdery mildew in strawberry fruits in: Proc. 10th Int. Epidemiol. Workshop. Cornell University, New York.

5. Asalf, B., Trandem, N., Stensvand, A., Wekesa, V. W., de Moraes, G. J., and Klingen, I. 2012. Influence of sulfur, powdery mildew, and the predatory mite Phytoseiulus persimilis on two-spotted spider mite in strawberry. Biol. Control 61:121-127.

6. Berrie, A., and Burgess, C. 1996. The effect of post-harvest epidemics of powdery mildew on yield and growth of strawberry cv. Elsanta. Acta Hort. 439:791-798.

7. Carisse, O., and Bouchard, J. 2010. Age-related susceptibility of strawberry leaves and berries to infection by Podosphaera aphanis. Crop Prot. 29:969-978.

8. Ficke, A., Gadoury, D. M., and Seem, R. C. 2002. Ontogenic resistance and plant disease management: A case study of grape powdery mildew. Phytopathology 92:671-675.

9. Ficke, A., Gadoury, D. M., Seem, R. C., and Dry, I. B. 2003. Effects of ontogenic resistance upon establishment and growth of Uncinula necator on grape berries. Phytopathology 93:556-563.

10. Ficke, A., Gadoury, D. M., Seem, R. C., Godfrey, D., and Dry, I. B. 2004. Host barriers and responses to Uncinula necator in developing grape berries. Phytopathology 94:438-445.
11. Gadoury, D. M., Asalf, B., Heidenreich, M. C., Herrero, M. L., Welser, M. J., Seem, R. C., Tronsmo, A. M., and Stensvand, A. 2010. Initiation, development, and survival of cleistothecia of Podosphaera aphanis and their role in the epidemiology of strawberry powdery mildew. Phytopathology 100:246-251.

12. Gadoury, D. M., Seem, R. C., Ficke, A., and Wilcox, W. F. 2001. The epidemiology of powdery mildew on Concord grapes. Phytopathology 91:948-955

13. Gadoury, D. M., Seem, R. C., Ficke, A., and Wilcox, W. F. 2003. Ontogenic resistance to powdery mildew in grape berries. Phytopathology 93:547-555

14. Gadoury, D. M., Seem, R. C., Wilcox, W. F., Henick-Kling, T., Conterno, L., Day, A., and Ficke, A. 2007. Effects of diffuse colonization of grape berries by Uncinula necator on bunch rots, berry microflora, and juice and wine quality. Phytopathology 97:1356-1365.

15. Gadoury, D. M., Stensvand, A., Seem, R. C., and Heidenreich, C. 2007. Ontogenic resistance of leaves, leaf folding and the distribution of mildew colonies in strawberry powdery mildew (Podosphaera macularis). Phytopathology 97(suppl.):S38.

16. Hesler, L. R., and Whetzel, H. C. 1917. Manual of Fruit Diseases. Macmillan, New York.

17. Jordan, V., and Hunter, T. 1972. The effect of glass cloche and coloured polyethylene tunnels on microclimate, growth, yield and disease severity of strawberry plants. J. Hort. Sci. 47:419-426.

18. Kanto, T., Matsuura, K., Yamada, M., Usami, T., and Amemiya, Y. 2008. UV-B radiation for control of strawberry powdery mildew. Acta Hort. 842:359-362.

19. Kanto, T., Miyoshi, A., Ogawa, T., Maekawa, K., and Aino, M. 2004. Suppressive effect of potassium silicate on powdery mildew of strawberry in hydroponics. J. Gen. Plant Pathol. 70:207-211.

20. Linde, M., and Debener, T. 2003. Isolation and identification of eight races of powdery mildew of roses (Podosphaera pannosa) (Wallr.: Fr.) de Bary and the genetic analysis of the resistance gene Rpp1. Theor. Appl. Genet. 107:256-262.

21. Maas, J. L. 1998. Compendium of Strawberry Diseases, 2nd Edition. The American Phytopathological Society, St. Paul, MN.

22. Mertely, J. C., MacKenzie, S. J., and Legard, D. E. 2002. Timing of fungicide applications for Botrytis cinerea based on development stage of strawberry flowers and fruit. Plant Dis. 86:1019-1024.

23. Minitab 14 Statistical Software. 2003. Minitab for windows. Minitab Inc. State College, PA.

24. Peries, O. S. 1962. Studies on strawberry mildew, caused by Sphaerotheca macularis (Wallr. ex Fries) Jaczewski. II. Host-parasite relationships on foliage of strawberry varieties. Ann. Appl. Biol. 50:225233.

25. Pertot, I., Zasso, R., Amsalem, L., Baldessari, M., Angeli, G., and Elad, Y. 2008. Integrating biocontrol agents in strawberry powdery mildew control strategies in high tunnel growing systems. Crop Prot. 27:622-631.

26. Sombardier, A., Dufour, M.-C., Blancard, D., and Corio-Costet, M.-F. 2010. Sensitivity of Podosphaera aphanis isolates to DMI fungicides: Distribution and reduced cross-seinsitivity. Pest Management Sci. 66:3543.

27. Sombardier, A., Savary, S., Blancard, D., Jolivet, J., and Willocquet, L. 2009. Effects of leaf surface and temperature on monocyclic processes in Podosphaera aphanis, causing powdery mildew of strawberry. Can. J. Plant Pathol. 31:439-448.

28. Suthaparan, A., Stensvand, A., Solhaug, K. A., Torre, S., Mortensen, L. M., Gadoury, D. M., Seem, R. C., and Gislerød, H. R. 2012. Suppression of powdery mildew (Podosphaera pannosa) in greenhouse roses by brief exposure to supplemental UV-B radiation. Plant Dis. 96:1653-1660.

29. Suthaparan, A., Stensvand, A., Torre, S., Herrero, M. L., Pettersen, R. I., Gadoury, D. M., and Gislerød, H. R. 2010. Continuous lighting reduces conidial production and germinability in the rose powdery mildew pathosystem. Plant Dis. 94:339-344.

30. Xiao, C. L., Chandler, C. K., Price, J. F., Duval, J. R., Mertely, J. C., and Legard, D. E. 2007. Comparison of epidemics of Botrytis fruit rot and powdery mildew of strawberry in large plastic tunnel and field production systems. Plant Dis. 85:901-909. 